\title{
Recovery from aphasia and neglect after subcortical stroke: neuropsychological and cerebral perfusion
} study

\author{
GIUSEPPE VALLAR, * DANIELA PERANI, $†$ STEFANO F CAPPA, \\ CRISTINA MESSA, $\uparrow$ GIAN LUIGI LENZI,§ FERRUCCIO FAZIO $\dagger$ \\ From the Department of Neurology, Policlinico Hospital, University of Milan, ${ }^{*}$ Department of Biomedical \\ Technology, San Raffaele Hospital, University of Milan, $\uparrow$ Department of Neurology, Niguarda Hospital, \\ Milan, $\ddagger$ and Department of Neuroscience, University of Rome§
}

SUMMARY Cortical regional cerebral perfusion was assessed by $\mathrm{N}, \mathrm{N}, \mathrm{N}^{1}$-trimethyl- $\mathrm{N}^{1}-(2)$ hydroxy-3-methyl-5-(I-123) iodobenzyl-1, 3-propanediamine 2 HCl I-123 (HIPDM) and single photon emission computerised tomography (SPECT) in six aphasic and two neglect patients with unilateral subcortical vascular lesions. Assessments were carried out both in the acute phase and after a period ranging from 1 to 6 months after stroke onset. In all patients an almost complete spontaneous recovery occurred and was associated with a significant improvement of cortical perfusion. A relationship between severity of aphasia and degree of cortical hypoperfusion was found, in both the acute and the follow up assessments, in the aphasic subgroup.

In the last 10 years ample evidence has come to light to indicate that $\mathrm{CT}$-assessed vascular lesions confined to subcortical regions, such as the thalamus, basal ganglia and white matter, may be associated with neuropsychological disorders. There have been frequent reports of aphasia and neglect occurring after left and right subcortical injury, respectively. ${ }^{12}$ In addition to the CT-assessed subcortical damage, patients with neuropsychological deficits typically show an associated hypoperfusion ${ }^{34}$ and a reduction of metabolism ${ }^{56}$ in the ipsilesional cortex. The cortical dysfunction appears to be a crucial causal factor, since patients without aphasia or neglect, who tend to have smaller subcortical lesions, have little, if any, ipsilesional cortical hypoperfusion. ${ }^{34}$

Most patients suffering from aphasia ${ }^{7-9}$ and neglect ${ }^{1011}$ caused by vascular subcortical lesions show a variable degree of recovery. The neural correlates of the restitution process are largely unknown, but some recent evidence from certain patients suffering from thalamic stroke appears to indicate that a reduction of ipsilesional cortical hypometabolism parallels recovery from aphasia and

Address for reprint requests: $\mathrm{Dr}$ G Vallar, Istituto di Clinica Neurologica, Via F Sforza 35, 20122, Milan, Italy.

Received 15 March 1988

Accepted 4 May 1988 neglect. ${ }^{5}$ In the present study we investigated neuropsychological function and cortical perfusion in eight aphasic and neglect patients with CT-assessed subcortical stroke lesions both in an early phase and months after stroke onset. This study aimed at assessing whether recovery from aphasia or neglect was associated with a significant reduction of hypoperfusion of cortical areas far removed from the subcortical lesion.

\section{Patients and methods}

Six left brain-damaged aphasic and two right brain-damaged neglect patients, suffering from a CT-assessed unilateral ischaemic or haemorrhagic lesion confined to the subcortical regions, were examined. All eight patients were right-handed and had no history of previous stroke or dementia. None of the patients underwent specific aphasic or neglect rehabilitation procedures. They had a mean age of 55.75 years (range 42-65) and a mean educational level of 4.25 years of schooling (range 0-8). Table 1 shows the site ${ }^{12}$ and size ${ }^{13}$ of the CT-assessed subcortical lesions; four haemorrhages and four infarctions, which did not appear to involve deep cortical areas buried in sulci such as the insula. Additional information concerning the initial assessment of the patients, other than cases R.L. and G.A., may be found in a previous study. ${ }^{4}$

Patients were examined during the acute or very recent phase by SPECT, carried out on the same day as the CT scan and neuropsychological assessments. The average interval between stroke onset and initial neuropsychological and SPECT assessments was 14.4 days (range $1-33$ ). The follow 
Table 1 CT scan data

\begin{tabular}{|c|c|c|c|c|c|c|}
\hline Case & $\begin{array}{l}\text { Age } \\
(y r)\end{array}$ & Sex & $\begin{array}{l}C T \text { scan } \\
\text { Site }\end{array}$ & $\begin{array}{l}\text { Size } \\
\left(\mathrm{cm}^{3}\right)\end{array}$ & $\begin{array}{l}\text { Doppler } \\
\text { Sonography }\end{array}$ & Angiography \\
\hline D.N.M. & 65 & $\mathbf{F}$ & I-L & 8.09 & normal & 1 \\
\hline B.M. & 55 & $\mathbf{M}$ & $\begin{array}{l}\mathrm{I}-\mathrm{L} \\
\mathrm{h} / \mathrm{b} \mathrm{CN}, \text { Fwm }\end{array}$ & $34 \cdot 70$ & 1 & normal \\
\hline A.T. & 65 & $\mathbf{F}$ & $\begin{array}{l}\text { H-L } \\
\text { LN }\end{array}$ & $23 \cdot 43$ & 1 & 1 \\
\hline C.F. & 49 & $\mathbf{F}$ & $\begin{array}{l}\text { H-L } \\
T\end{array}$ & $23 \cdot 80$ & 1 & 1 \\
\hline R.L. & 54 & $\mathbf{F}$ & $\begin{array}{l}\text { I-L } \\
T\end{array}$ & $2 \cdot 73$ & normal & 1 \\
\hline G.A. & 57 & $\mathbf{M}$ & $\begin{array}{l}\text { H-L } \\
\text { LN, ic, ec }\end{array}$ & $61 \cdot 4$ & 1 & 1 \\
\hline Z.G. & 42 & $\mathbf{M}$ & $\begin{array}{l}\text { I-R } \\
\text { pl ic, cr }\end{array}$ & $53 \cdot 24$ & 1 & RCCA Occl. \\
\hline R.G. & 59 & $\mathbf{M}$ & $\begin{array}{l}\text { H-R } \\
\text { T pl ic, POwm }\end{array}$ & $33 \cdot 30$ & 1 & 1 \\
\hline
\end{tabular}

$\mathbf{R}=$ right; $\mathrm{L}=$ left $\mathbf{H}=$ haemorrhage $\mathrm{I}=$ infarct $\mathbf{C C A}=$ common carotid artery; $\mathrm{T}=$ thalamus; $\mathrm{h} / \mathrm{b} \mathbf{C N}=$ head/body caudate nucleus; $\mathrm{LN}=$ lentiform nucleus; $\mathrm{cr}=$ corona radiata; $\mathrm{F} / \mathrm{P} / \mathrm{O} \mathrm{wm}=$ frontoparieto-occipital periventricular white matter; $\mathrm{pl}$ ic $=$ posterior $\operatorname{limb}$ internal capsule; $\mathrm{ec}=$ extreme capsule.

up neuropsychological and SPECT assessments were performed 3.2 months later (range 1-5.6).

Neuropsychological assessment The six left-brain damaged patients were given an aphasia examination, comprising a number of subtests, to assess the main aspects of language behaviour (auditory verbal comprehension, oral expression, repetition, reading and writing). The battery, described in detail elsewhere, ${ }^{4}$ included the following sub-tests: (1) conversational and expository speech; (2) oral naming of visual objects; (3) description naming; (4) token test; (5) letter, word and sentence repetition; (6) auditory forward digit span; (7) reading letters, words, nonwords and comprehension of written words and sentences; (8) written naming; (9) word fluency with phonemic and semantic cues. Cut off scores, computed on data from control subjects, were available for all subtests.

The two right-brain damaged patients were given a neglect battery, described in detail elsewhere, ${ }^{4}$ which included the following subtests for the assessment of extrapersonal neglect: (1) cancellation task; (2) reading task; (3) tactile exploratory task. Tests for detecting anosognosia and personal neglect were also given. In all the neglect tasks the controls' performance was errorless.

Brain tomographic assessment The SPECT I-123 HIPDM method for the assessment of regional cerebral blood flow (rCBF) was used. ${ }^{415}$ Eight consecutive slices from the orbitomeatal (OM) line up to the vertex were taken for each subject. In order to avoid possible artefacts due to the presence of sulci, the two slices corresponding to the vertex were excluded from the analysis. The two slices corresponding to the cerebellum (OM and $1.3 \mathrm{~cm}$ above) were not considered for this study. For each of the four supratentorial cerebral slices, $2 \cdot 7,3 \cdot 9,5 \cdot 1$ and $6 \cdot 3 \mathrm{~cm}$ above the OM line, 12 symmetrical regions of interest (ROIs), $4 \times 4$ pixels $(2.5 \times 2.5 \mathrm{~cm})$ were examined; six in the left and six in the right hemisphere. The ROIs were located on the cortical ribbon; two in the anterior, two in the middle and two in the posterior cortical regions. Counts of the two homolateral anterior, middle and posterior ROIs were averaged, thus obtaining three count values (anterior, middle and posterior) for each hemisphere in each supratentorial slice.

Data analysis For both the initial and the follow up SPECT examinations, a semiquantitative assessment of rCBF was performed by means of a relative perfusion index between the two hemispheres, computed in nine normal subjects by the left to right count ratio. An overall hemispheric index value of 1.00 (SD 0.08) was found in the control group. In the eight brain-damaged patients the index was defined as the ratio between the count values of a given $\mathrm{ROI}$ in the affected hemisphere and the symmetrical ROI in the normal hemisphere.

Index values equal/lower/higher than 1.00 indicate no interhemispheric differences, a reduction or an increase of perfusion in the damaged hemisphere, respectively. Index values ranging from 0.84 to 1.16 were considered normal.

Three index values (anterior, middle and posterior) for each of the four slices were calculated by the ratio between symmetrical anterior, middle and posterior count values, yielding 12 index values for each subject for each (initial and follow up) SPECT assessment. These data were used for a repeated measurements analysis of variance, following a randomised block factorial design. ${ }^{16}$ The main factors in this analysis were time (initial and follow up SPECT assessments), region (anterior, middle and posterior) and slice (four supratentorial slices).

An additional analysis (paired $t$ test) aimed at assessing whether the number of index values outside the normal range $(1 \cdot 00$, SD 2$)$ differed in the initial and follow up assessments.

\section{Results}

The neuropsychological performances of the eight patients in the initial and follow up assessments are shown in tables 2 and 3. From these tables it can be seen that the six aphasic left brain-damaged patients showed marked improvement in their aphasic picture and neglect vanished in the two right brain-damaged patients.

The average index values in the initial and follow up assessments are shown in fig 1; cerebral perfusion, which was remarkably reduced in the anterior and middle regions, improved over time. An analysis of variance revealed that the main effects of time of SPECT assessment $(F=10.515 ;$ df 1,$7 ; p<0.025)$, of region $(F=10.744 ;$ df 2,$14 ; p<0.005)$ and of slice $(F=5.451 ;$ df 3,$21 ; p<0.01)$ were significant. The time $\times$ region interaction was significant $(F=5.319$; df 2,$14 ; \mathrm{p}<0.025)$, while the time $\times$ slice $(\mathrm{F}<1$; df 3,21 ; NS), the region $\times$ slice $(\mathrm{F}<1$; df 6,$42 ; \mathrm{NS})$ and the time $\times$ region $\times$ slice $(F=1 \cdot 046 ;$ df 6,$42 ;$ NS) interactions failed to reach significance level. Tests of simple main effects showed a significant difference between the initial and follow up assessments in the middle $(F=6.82$; df 1,$7 ; p<0.05)$, but not in the anterior $(F=3.712$; df 1,7 ; NS) and posterior $(F<1$; df 1,7 ; NS) regions. Finally, a significant difference among regions was found in the initial $(F=7.438$, df $2,14 ; p<0.025)$ but not in the follow up $(F=2.737$; df 2,14 ; NS) assessment. 
No index values above the normal range were found. The average abnormally low index values were 6.87 and 4.5 in the initial and follow-up assessments respectively $(t=2.516$, df $7, \mathrm{p}<0.05)$, showing that recovery from aphasia or neglect is associated with a reduction in the extent of cortical hypoperfusion.

Table 2 Neuropsychological performances in the initial (I) and follow up (II) assessments of six aphasic left

brain-damaged patients. Time interval between assessments is in months. The scores below the cut off are underlined

\begin{tabular}{|c|c|c|c|c|c|c|c|}
\hline Case & & D.N.M. & B.M. & A.T. & C.F. & R.L. & G.A. \\
\hline Interval & & 3.4 & 1 & $3 \cdot 6$ & 2 & 56 & $2 \cdot 2$ \\
\hline $\mathrm{OE}$ & -I & $\begin{array}{l}\text { NF } \\
\text { NF }\end{array}$ & $\begin{array}{l}\text { NF } \\
\text { NF }\end{array}$ & $\begin{array}{l}\text { F } \\
\text { NA }\end{array}$ & $\begin{array}{l}\text { NF } \\
\text { NA }\end{array}$ & $\begin{array}{l}\mathbf{F} \\
\text { NA }\end{array}$ & $\begin{array}{l}\text { NA } \\
\text { NA }\end{array}$ \\
\hline $\mathrm{ON}(28 \cdot 25)$ & -II & $\frac{0}{5}$ & $\frac{0}{0}$ & $\begin{array}{l}31.25 \\
28.25\end{array}$ & $\frac{19 \cdot 25}{30}$ & $\frac{26.25}{31 \cdot 25}$ & $\begin{array}{l}28 \cdot 6 \\
31 \cdot 25\end{array}$ \\
\hline $\mathrm{DN}(33.5)$ & & $\frac{12}{18}$ & $\frac{0}{0}$ & $\begin{array}{l}31 \cdot 50 \\
38\end{array}$ & $\frac{25.75}{32.75}$ & $\frac{24.75}{32.25}$ & $\begin{array}{l}34 \\
36 \cdot 1\end{array}$ \\
\hline AWC(32) & & $\frac{30}{32}$ & $\frac{0}{17}$ & & $\begin{array}{l}32 \\
32\end{array}$ & $\frac{31}{32}$ & $\frac{30}{32}$ \\
\hline ATT(29) & -II & $\frac{19}{23}$ & $\frac{0}{7}$ & $\frac{24}{31}$ & $\frac{24}{31}$ & $\frac{27}{33}$ & $\begin{array}{l}29 \\
34\end{array}$ \\
\hline LWR(34) & -I & $\frac{21}{27}$ & $\frac{1}{0}$ & $\frac{33}{34}$ & $\begin{array}{l}34 \\
34\end{array}$ & $\begin{array}{l}34 \\
34\end{array}$ & 34 \\
\hline SR(13.04) & -I & $\frac{0}{3}$ & $\frac{0}{0}$ & $\frac{13}{15.5}$ & $\frac{9}{15}$ & $\begin{array}{l}20 \\
20\end{array}$ & $\frac{11}{14}$ \\
\hline $\operatorname{DS}(3.75)$ & -I $_{\text {II }}$ & $\frac{1}{4}$ & 0 & $\begin{array}{l}4 \\
4\end{array}$ & $\begin{array}{l}4 \\
5\end{array}$ & $\begin{array}{l}5 \\
5\end{array}$ & $\begin{array}{l}4 \\
4\end{array}$ \\
\hline$R(64)$ & -I & 14 & 0 & $\frac{60}{59}$ & $\frac{25}{62}$ & $\begin{array}{l}64 \\
64\end{array}$ & $\begin{array}{l}64 \\
64\end{array}$ \\
\hline VWC(12) & -I & $*^{5}$ & 0 & $\begin{array}{l}12 \\
12\end{array}$ & $\frac{10}{12}$ & $\begin{array}{l}12 \\
12\end{array}$ & $\begin{array}{l}12 \\
12\end{array}$ \\
\hline VTT(8) & -I & $\frac{4 \cdot 5}{6}$ & 0 & $\frac{7}{11 \cdot 5}$ & $\begin{array}{r}9 \\
12\end{array}$ & $\begin{array}{l}12 \\
13 \cdot 5\end{array}$ & $1 \frac{7}{3 \cdot 5}$ \\
\hline $\mathrm{WN}(12)$ & -I & $\frac{0}{1}$ & 0 & $\frac{0}{6}$ & $\frac{1}{2}$ & $1 \frac{3}{2}$ & $\frac{10}{9}$ \\
\hline FWF(17) & $\begin{array}{l}\text {-I } \\
\text {-II }\end{array}$ & $1 \frac{0}{2}$ & 0 & 29 & $\frac{12 \cdot 5}{13 \cdot 5}$ & $\frac{14}{18}$ & $\begin{array}{l}2 \overline{0} \cdot 2 \\
19 \cdot 50\end{array}$ \\
\hline CWF(25) & -I $^{\text {II }}$ & $2 \frac{0}{2}$ & 0 & $\frac{19}{32}$ & $\frac{14}{22}$ & $\frac{19}{26}$ & $\begin{array}{l}26 \cdot 25 \\
27\end{array}$ \\
\hline
\end{tabular}

$\mathrm{OE}=$ oral expression $(\mathrm{NA}=$ nonaphasic, $\mathrm{F}=$ fluent,$\quad \mathrm{NF}=$ nonfluent); $\mathrm{O} / \mathrm{D} / \mathrm{WN}=$ oral/description/written naming; $\mathrm{A} / \mathrm{VWC}=$ auditory/visual word comprehension; A/VTT = auditory/visual Token Test; $\mathbf{L} / \mathbf{W} / \mathbf{S R}=$ letter/word/sentence repetition; $\mathrm{DS}=$ digit span; $\mathbf{R}=$ reading; $\mathbf{F} / \mathrm{CWF}=$ phonemic/categorial word fluency. $*$ refused.

Table 3 Neuropsychological performances in the initial (I) and follow up (II) assessments of two neglect right brain-damaged patients. The scores represent omission in the left contralesional side of space. Control subjects are zero

\begin{tabular}{llcl}
\hline Case & & $Z . G$. & $R . G$. \\
\hline (months) & & $2 \cdot 4$ & $4 \cdot 6$ \\
CT & -I & 0 & 6 \\
RT & -II & 0 & 0 \\
IET & -II & 3 & $*$ \\
A & -I & 0 & 0 \\
II & -II & 14 & 0 \\
PN & -II & 0 & 0 \\
& -I & 0 & 0 \\
& -II & 0 & 1 \\
\hline
\end{tabular}

CT = cancellation task; $\mathrm{RT}=$ reading task; $\mathrm{TET}=$ tactile exploratory task; $\mathrm{A}=$ anosognosia; $\mathrm{PN}=$ personal neglect. ${ }^{*}=$ illiterate.
As previously mentioned, all six left brain-damaged patients showed a more or less pronounced degree of recovery from the initial aphasic deficit. It is however apparent from table 2 that they may be readily subdivided into two subgroups, according to the overall severity of aphasia. Cases D.N.M. and B.M., respectively a Broca's and global aphasic, showed severe deficit in both the initial and follow up neuropsychological assessments. The remaining four cases (A.T., C.F., R.L. and G.A.) suffered from a milder

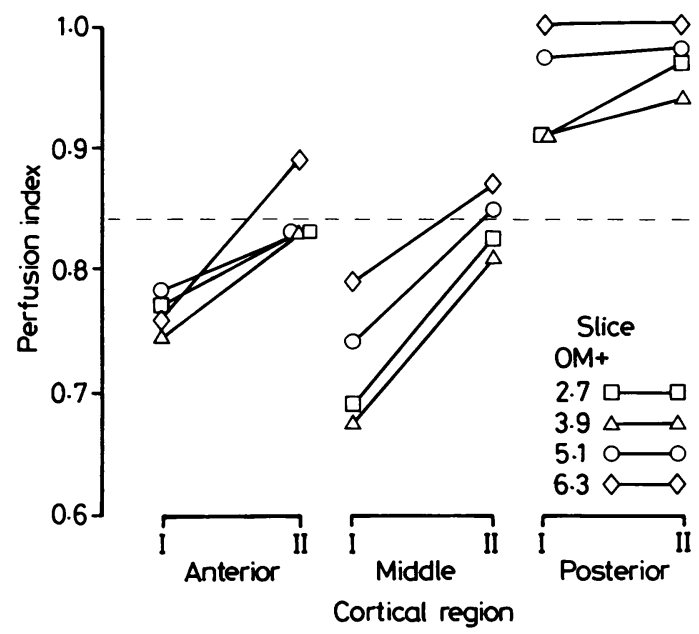

Fig 1 Mean index of relative perfusion values of six left brain-damaged aphasic and two right brain-damaged neglect patients with subcortical stroke lesions. I and II: initial and follow up SPECT assessments. Dashed line: cut off (0.84) of perfusion index.

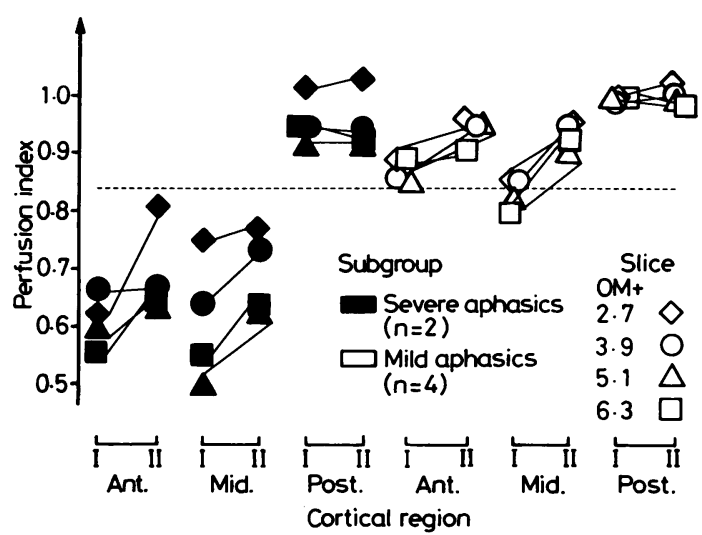

Fig 2 Mean index of relative perfusion values of two severe and four mild aphasic left brain-damaged patients. Ant./Mid./Post. anterior/middle/posterior. I and II and dashed line: see fig 1 . 

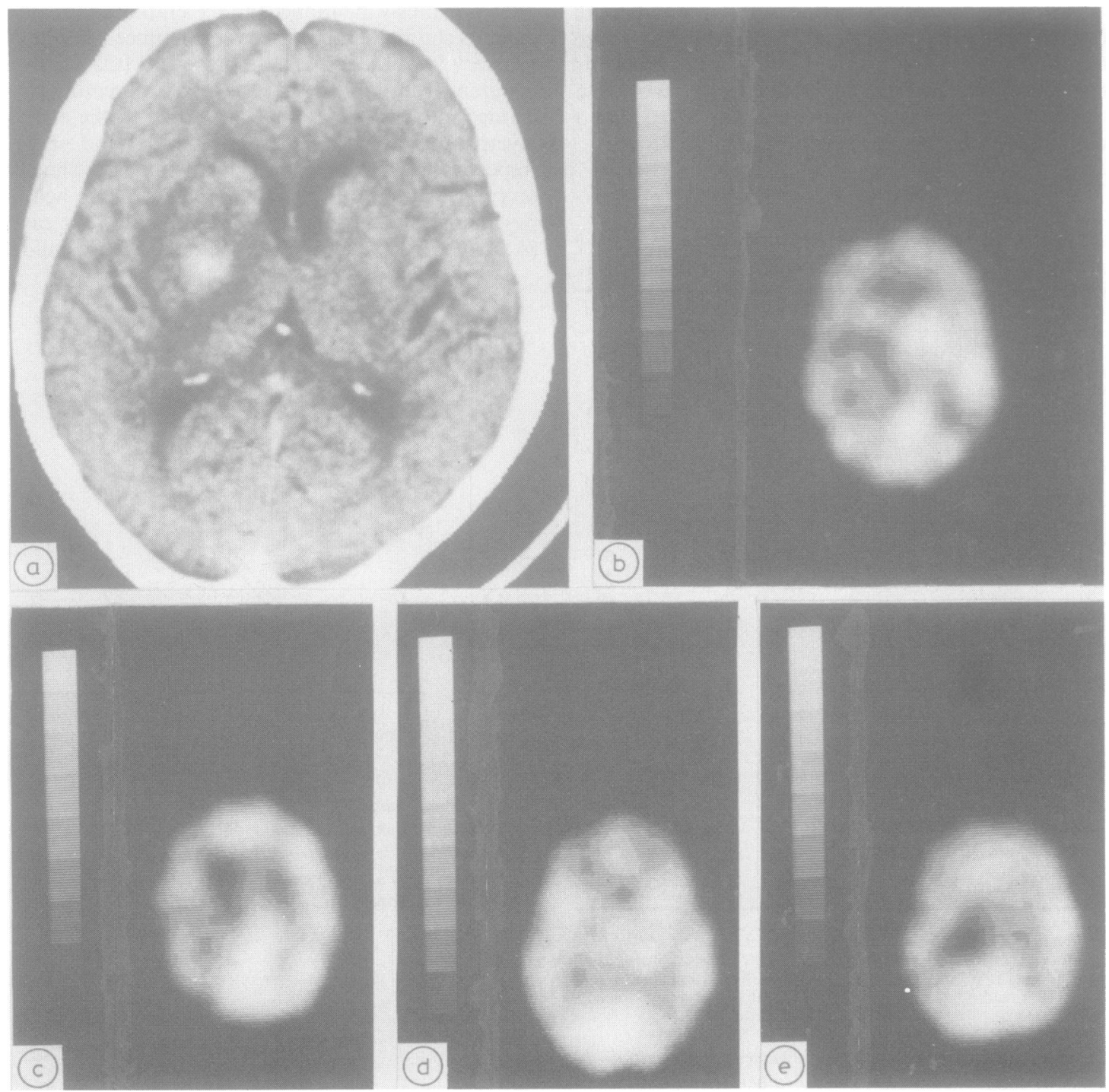

Fig 3 Case A.T. (A) CT scan showing a haematoma involving the left lentiform nucleus (B.C.) initial SPECT $(O M+5.1 \mathrm{~cm}$ and $O M+6.3 \mathrm{~cm})$ showing hypoperfusion in frontoparietal cortical areas in the left hemisphere (D.E.) follow up SPECT $(O M+5 \cdot 1 \mathrm{~cm}$ and $O M+6.3 \mathrm{~cm})$ showing reduction of cortical hypoperfusion.

initial aphasic disorder. On the follow up assessment, two patients (G.A. and R.L.) were left with isolated disorders of written and oral description naming, respectively. Two cases (A.T. and C.F.) had a comparatively wider residual deficit including mild auditory word comprehension (A.T.), word fluency and description naming (C.F.), reading and written naming difficulties.

Figure 2 shows the average index values of the two subgroups of patients (severe and mild aphasics) in the initial and follow up assessments. It is apparent that the two severe aphasics, during both the recent and follow up phases after stroke, had a major cortical hypoperfusion in the anterior and middle cerebral regions, even though some improvement took place. Conversely, the four mild aphasics displayed a slight cortical blood flow reduction in the middle cerebral regions in the initial assessment only. These data were 


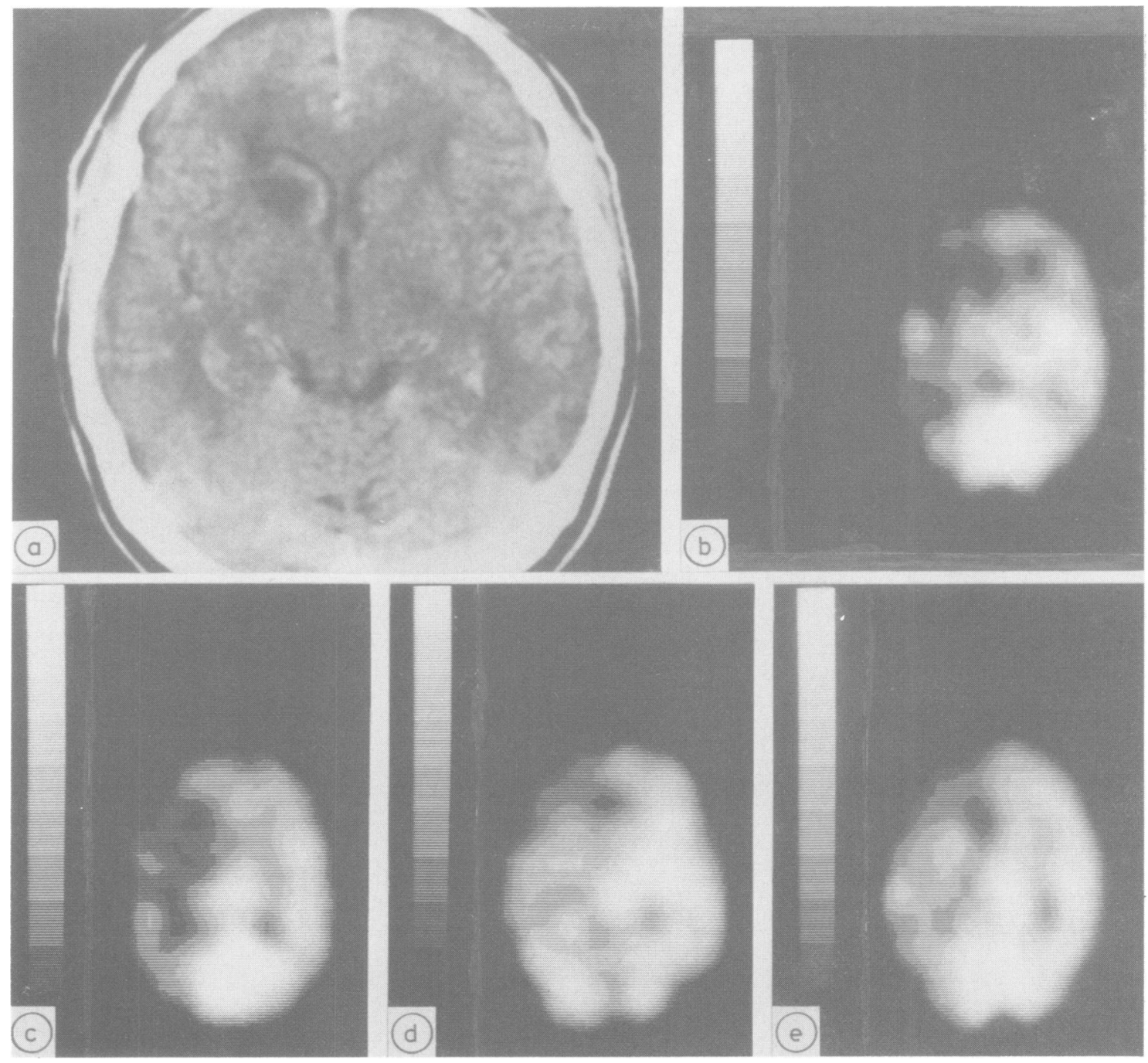

Fig 4 Case B.M. (A) CT scan showing an ischaemic lesion in the left caudate nucleus and the frontal white matter (B.C.) initial SPECT $(O M+5 \cdot 1 \mathrm{~cm}$ and $O M+6 \cdot 3 \mathrm{~cm})$ showing massive hypoperfusion in frontoparietal cortical areas in the left hemisphere (D.E.) follow up SPECT $(O M+5 \cdot 1$ and $O M+6 \cdot 3 \mathrm{~cm})$ showing reduction of cortical hypoperfusion.

used for a repeated measurements analysis of variance, following a randomised block factorial design. ${ }^{16}$ The main factors in this analysis were subgroup (severe and mild aphasics), time (initial and follow up SPECT assessments) region (anterior, middle and posterior) and slice (four supratentorial slices). The main effects of group $(F=56.938 ;$ df 1,$4 ; p<0.005)$, of time $(F=49.333 ;$ df 1,$4 ; p<0.005)$ of region $(F=23.643 ;$ df 2, 8; $p<0.001)$ and of slice $(F=3.885 ;$ df 3,$12 ; p<0.05)$ were significant. The region $\times$ group interaction was significant $(F=7$; df
2, 8; $<<0.025$ ). All other interactions failed to reach significance level.

The CT-assessed subcortical lesions and the initial and follow up SPECT studies of three patients are shown in figs 3-5. Case A.T. (fig 3) had a comparatively milder initial aphasic disorder and showed an almost complete recovery. Case B.M. (fig 4) was severely aphasic in both the initial and follow up assessments, even though some improvement occurred. Case R.G. (fig 5) showed a complete recovery from neglect. 


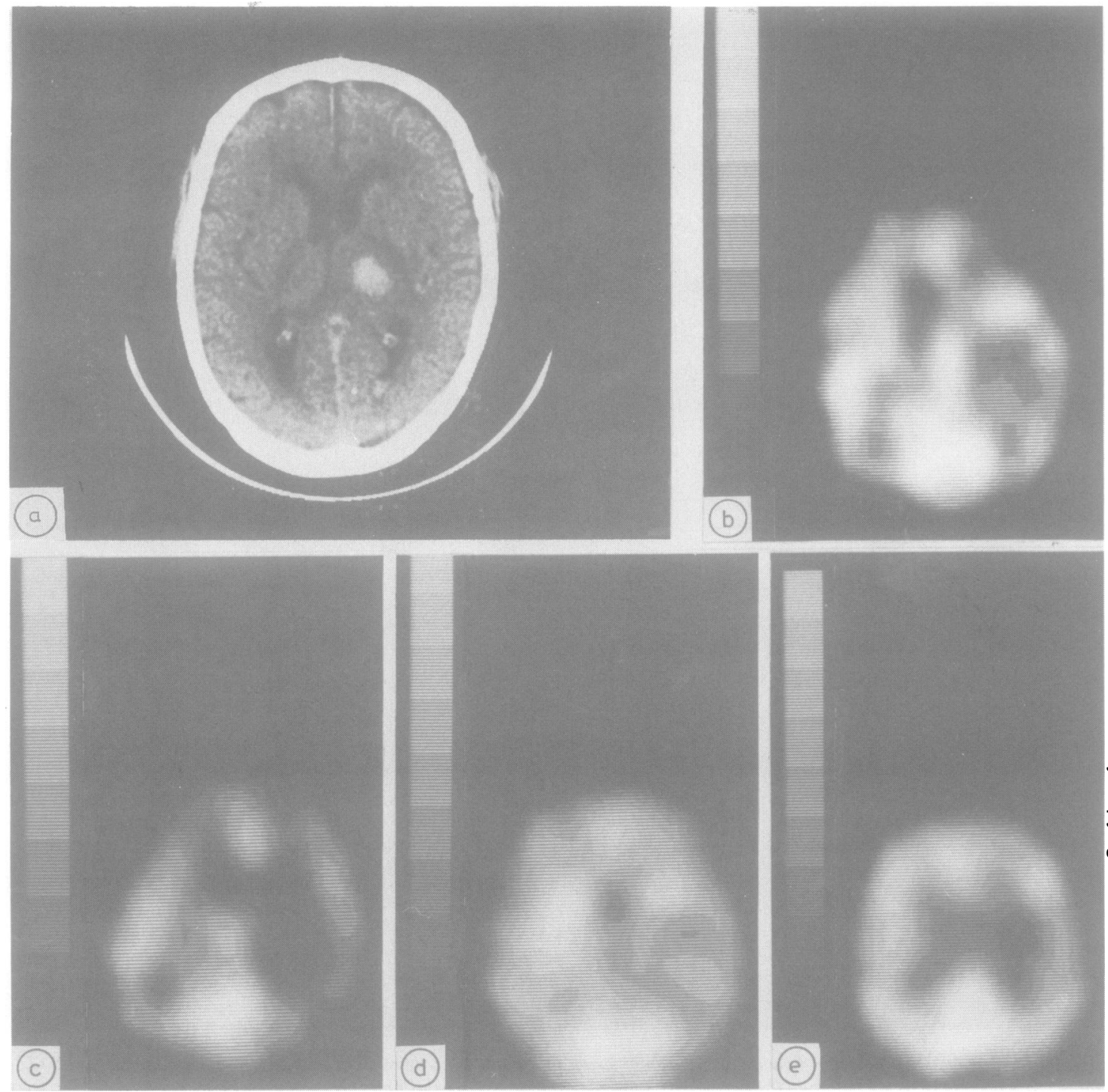

Fig 5 Case R.G. (A) CT scan showing a right thalamic haematoma. (B.C.) initial SPECT (OM + $3.9 \mathrm{~cm}$ and $O M+6 \cdot 3$ $\mathrm{cm}$ ) showing massive hypoperfusion in frontotemporoparietal cortical areas in the right hemisphere (D.E.) follow up SPECT $(O M+3.9 \mathrm{~cm}$ and $O M+6.3 \mathrm{~cm})$ showing reduction of cortical hypoperfusion.

\section{Discussion}

The results of our study indicate that in patients with neuropsychological deficits due to subcortical stroke there is a close parallel between behavioural recovery and cortical perfusion: complete recovery is associated with correction of cortical blood flow, while a lesser degree of improvement is found in patients with persistent cortical hypoperfusion. Consistent with the present findings, in four patients with unilateral thalamic lesions who had recovered from aphasia or neglect, cortical hypometabolism was significantly improved in a follow up positron emission tomography (PET) study of cortical oxygen and glucose utilisation. ${ }^{5}$ These findings suggest that recovery after subcortical lesions is related to the regression of the functional abnormalities occurring in distant structures which appear undamaged on CT scan. ${ }^{4}$ As men- 
tioned elsewhere, ${ }^{4}$ these remote effects may be attributed to a decrease of neuronal activity, caused by interruption of input from afferent fibre pathways, ${ }^{17}$ while a vascular mechanism ("ischaemic penumbra") ${ }^{18}$ is unlikely, at least in patients without large vessel occlusions or with thalamic stroke.

Experimental evidence showing correlations between regression of remote effects and behavioural recovery is available. Deuel, ${ }^{19}$ who investigated the behavioural effects of ablation of the frontal or parietal association cortices in the monkey, found hypometabolism in a number of cortical and subcortical areas undamaged by the lesions, while the animals showed contralesional visual neglect. Conversely, in recovered animals a regression of these remote effects was shown in the caudate nucleus, putamen and globus pallidus. Similarly, unilateral ablation of the precentral cortex, which produced a contralateral hemiplegia, was associated in the monkey with a metabolic reduction in the ipsilateral basal ganglia. ${ }^{20}$ During recovery of motor activity a restoration of metabolism was found, maximal in ipsilateral structures directly connected to the cortex such as the caudate nucleus and the putamen. ${ }^{21}$

The hypothesis that recovery could be due to regression of functional de-activation ("diaschisis") in brain regions remote but connected to the primarily injured areas was originally introduced by von Monakow. ${ }^{22}$ Recent technological advances in the study of remote functional effects of stroke have revived interest in this concept. ${ }^{23}$ While this mechanism appears to account for the clinical improvement of aphasic and neglect patients with strokes confined to the subcortical regions, its role in the more common case of cortical lesions is much less clear. While several PET investigations have revealed remote effects in cortical aphasias, ${ }^{24}$ studies of the recovery process in neuropsychological disorders are scanty. A number of studies using the Xe 133 inhalation method for the assessment of $\mathrm{rCBF}$ have focused mainly on the issue of differences in the contribution of the two hemispheres to recovery. The two patients studied by Yamaguchi et $a l^{25}$ showed a good recovery from aphasia associated, during activation procedures, with an increase in rCBF in a right hemisphere region homologous to Broca's area. In a complex study involving a language activation task, Knopman et $a l^{26}$ found a correlation between reduction of hypoperfusion in the left posterior temporal and inferiorparietal areas and recovery of auditory comprehension. In Demeurisse and Capon's ${ }^{27}$ study the best indicator for a good prognosis in recovery from aphasia was the activation of the left hemisphere. In recovered patients, however, the bihemispheric pattern of cortical activation was more extensive than in normal subjects. In the case of neglect, functional investigations of recovery in patients with cortical lesions are, to our knowledge, not available. To summarise: in subcortical lesions there is clear evidence that diaschisis of the ipsilesional cortex is a crucial factor for the appearance of neuropsychological symptoms and that its regression is related to clinical improvement. In the case of cortical lesions a more complex pattern emerges, where both the spared cortical areas of the left hemisphere and regions of the contralateral hemisphere appear to be involved in recovery from aphasia.

Finally, remote effects in subcortical structures have been shown to occur also in cortical aphasias. ${ }^{24}$ However, human studies correlating regression of diaschisis and behavioural recovery which could corroborate the pattern suggested by the aforementioned experimental data, ${ }^{1921}$ are not available. Differences in mechanisms of recovery could reflect the differential contribution of cortical and subcortical areas to neuropsychological functions. There is the possibility that, in line with the classical views (see refs 12 for review), the primary neurological substrate of language and spatial abilities is the cerebral cortex, while subcortical structures, such as the thalamus, have a non-specific, that is, activatory, role. If this is the case, the occurrence of neuropsychological deficits after subcortical lesions would always reflect a functional cortical derangement. Conversely, in the case of a cortical lesion a given deficit (such as auditory comprehension) could be produced either by a primary damage of the relevant areas (such as Wernicke's area) or by a remote effect due to a lesion in a connected brain region. These putative mechanisms may be expected to have different implications for recovery. On this basis, permanent and temporary behavioural deficits should be associated with the structural damage of a committed region and its functional derangement (but see ref 23 for a discussion of the possibility of a "permanent diaschisis"). Some evidence supporting this view is available. In Knopman et al's. study, ${ }^{26}$ auditory comprehension was recovered only when the anatomical lesion spared Wernicke's area and was related to the regression of transient hypoperfusion in this region. On the contrary, when this area was directly damaged, recovery was poor and rCBF activation studies indicated a possible contribution from the right hemisphere. Similarly, in a recent PET study of hemianopic patients, ${ }^{28}$ vision was recovered only when the occipital lobe was spared and related to an improvement of hypometabolism in the striatal cortex.

If aphasia and neglect produced by subcortical stroke reflect a functional temporary cortical derangement, recovery, as compared with neuropsychological deficits associated with primary damage of the putatively committed cortical regions, should be faster and 
more complete. The available evidence, however, does not support this prediction unequivocally. Demeurisse et $a l^{29}$ found equal recovery rates in aphasic patients with cortical or deep lesions, the only difference being that in the latter no relationship between lesion size and recovery rate was found. Conversely, in the study of Olsen $e t a l^{3}$ patients with subcortical lesions recovered better than aphasics with cortical damage. Finally, no clear-cut differences in recovery rates for neglect associated with cortical and subcortical injury have been detected. ${ }^{10}$

These findings seem consistent with the hypothesis that cognitive functions are mediated by corticosubcortical loops, where a number of subcortical structures may also have specific functional roles. There is clinical evidence concerning the role of the left thalamus in language processing to support this view. Aphasic disorders produced by thalamic stroke (semantic errors in naming and spontaneous speech, preserved repetition) $)^{30-32}$ suggest a participation of thalamic structure, in possible association with the marginal cortical areas of the left hemisphere, ${ }^{3033} 34$ to the neural network subserving the lexical-semantic level of processing. Follow up PET studies of patients with neuropsychological disorders associated with different lesion sites are likely to provide important clues to the neurological mechanism underlying recovery.

This paper was supported in part by grants from the Consiglio Nazionale della Ricerche and the Ministero della Pubblica Istruzione.

\section{References}

1 Cappa SF, Vignolo LA. CT scan studies of aphasia. Human Neurobiology 1983;2:129-34.

2 Vallar G, Perani D. The anatomy of spatial neglect in humans. In: Jeannerod M, ed. Neurophysiological and Neuropsychological Aspects of Spatial Neglect. Amsterdam: Elsevier Science Publishers, 1987:235-58.

3 Skyhoj Olsen T, Bruhn P, Oberg RGE. Cortical hypoperfusion as a possible cause of "Subcortical aphasia". Brain 1986;109:393-410.

4 Perani D, Vallar G, Cappa SF, Messa C, Fazio F. Aphasia and neglect after subcortical stroke. A clinical/cerebral perfusion correlation study. Brain 1987;110:1211-29.

5 Baron JC, D'Antona R, Pantano P, Serdaru M, Samson Y, Bousser MG. Effects of thalamic stroke on energy metabolism of the cerebral cortex. Brain 1986;109:1243-59.

6 Metter EJ, Jackson C, Kempler D, et al. Left hemisphere intracerebral hemorrhages studied by (F-18)-fluorodeoxyglucose PET. Neurology 1986;36:1155-62.

7 Damasio AR, Damasio H, Rizzo M, Varney N, Gersh F. Aphasia with nonhemorrhagic lesions in the basal ganglia and internal capsule. Arch Neurol 1982;39:15-20.

8 Mohr JP. Thalamic lesions and syndromes. In: Kertesz A, ed. Localization in Neuropsychology. New York: Academic Press 1983:269-93.

9 Cambier J, Graveleau P. Thalamic syndromes. In: Frederiks JAM, ed. Handbook of Clinical Neurology, Vol. 1(45): Clinical Neuropsychology. Amsterdam: Elsevier Science Publishers, 1985:87-98.
10 Hier DB, Mondlock J, Caplan LR. Recovery of behavioral abnormalities after right hemisphere stroke. Neurology 1983;33:345-50.

11 Ferro JM, Kertesz A, Black SE. Subcortical neglect; quantitation, anatomy and recovery. Neurology 1987;37:1487-92.

12 Matsui J, Hirano A. An Atlas of the Human Brain for Computerized Tomography. Tokyo: Igaku-Shoin 1978.

13 Kertesz A, Harlock W, Coates R. Computer tomographic localization, lesion size and prognosis in aphasia and nonverbal impairment. Brain Lang 1979;8:34-50.

14 Fazio F, Lenzi GL, Gerundini P, et al. Tomographic assessment of regional cerebral perfusion using intravenous I-123 HIPDM and a rotating gamma camera. J Comput Assist Tomogr 1984;8:911-21

15 Lucignani G, Nehlig A, Blasberg R, et al. Metabolic and kinetic considerations in the use of [125 I] HIPDM for quantitative measurement of regional cerebral blood flow. $J$ Cereb Blood Flow Metab 1985;5:86-96.

16 Kirk RE. Experimental Design: Procedures for the Behavioural Sciences. Belmont, CA: Brooks/Cole 1968.

17 Powers WJ, Raichle ME. Positron emission tomography and its application to the study of cerebrovascular disease in man. Stroke 1985;16:361-76.

18 Astrup J, Siesjo BK, Symon L. Thresholds in cerebral ischemia: the ischemic penumbra. Stroke 1981;12:723-5.

19 Deuel RK. Neural dysfunction during hemineglect after cortical damage in two monkey models. In: Jeannerod $M$ ed. Neurophysiological and Neuropsychological Aspects of Spatial Neglect. Amsterdam: Elsevier Science Publishers, 1987:315-34.

20 Dauth GW, Gilman S, Frey KA, Penney JB jr. Basal ganglia glucose utilization after recent precentral ablation in the monkey. Ann Neurol 1985;17:431-8.

21 Gilman S, Dauth GW, Frey KA, Penney JB jr. Experimental hemiplegia in the monkey: basal ganglia glucose activity during recovery. Ann Neurol 1987;22:370-6.

22 Monakow $\mathrm{C}$ von. Die Lokalisation im Grosshirn und der Abban der Funktion durch Kortikale Herde. Wiesbaden: Bergmann, 1914.

23 Feeney DM, Baron JC. Diaschisis. Stroke 1986;17:817-30.

24 Metter EJ. Neuroanatomy and physiology of aphasia: evidence from positron emission tomography. Aphasiology 1987;1:3-33.

25 Yamaguchi F, Meyer JS, Sakai F, Yamamoto M. Case reports of three dysphasic patients to illustrate rCBF responses during behavioral activation. Brain Lang 1980;9:145-58.

26 Knopman DS, Rubens AB, Selnes OA, Klassen AC, Meyer MW. Mechanisms of recovery from aphasia: evidence from serial Xenon 133 cerebral blood flow studies. Ann Neurol 1984;15:530-5.

27 Demeurisse G, Capon A. Language recovery in aphasic stroke patients: clinical, CT and CBF studies. Aphasiology 1987;1:301-15.

28 Bosley TM, Dann R, Silver FL, et al. Recovery of vision after ischemic lesions: Positron emission tomography. Ann Neurol 1987;21:444-50.

29 Demeurisse G, Capon A, Verhas M. Prognostic value of computed tomography in aphasic stroke patients. Eur Neurol 1985;24:134-9.

30 Cappa SF, Vignolo LA. "Transcortical" features of aphasia following left thalamic hemorrhage. Cortex 1979;15:121-9.

31 Crosson B. Role of the dominant thalamus in language. Psychol Bull 1984;96:491-517.

32 Wallesch C-W, Papagno C. Subcortical aphasia. In: Rose FC Whurr R, Wyke MA, eds. Aphasia. London: Cole and Whurr, 1988:256-87.

33 Cappa SF, Cavallotti G, Vignolo LA. Phonemic and lexical errors in fluent aphasia: correlation with lesion site. Neuropsychologia 1981;19:171-7.

34 Vallar G, Papagno C, Cappa SF. Latent dysphasia after left hemisphere lesions: a lexical-semantic and verbal memory deficit. Aphasiology (in press). 